\title{
The Role of Metal-Doped into Magnetite Catalysts for the Photo-Fenton Degradation of Organic Pollutants
}

\author{
Xuan Sang Nguyen*, Kim Dinh Ngo \\ Environmental Institute, Vietnam Maritime University, Hai Phong, Vietnam \\ Email: *sangnx.vmt@vimaru.edu.vn
}

How to cite this paper: Nguyen, X.S. and Ngo, K.D. (2018) The Role of Metal-Doped into Magnetite Catalysts for the Photo-Fenton Degradation of Organic Pollutants. Journal of Surface Engineered Materials and Advanced Technology, 8, 1-14. https://doi.org/10.4236/jsemat.2018.81001

Received: October 19, 2017

Accepted: November 27, 2017

Published: November 30, 2017

Copyright ( 92018 by authors and Scientific Research Publishing Inc. This work is licensed under the Creative Commons Attribution International License (CC BY 4.0). http://creativecommons.org/licenses/by/4.0/

\begin{abstract}
Recently, the incorporation of transition metals into magnetite increasing the heterogeneous Fenton catalytic activity of magnetite with high efficiency and interesting magnetic properties applied for degradation of organic pollutants in water purification and wastewater treatment have attracted more and more researchers. In this review, using of one or some metal doped magnetite based systems in heterogeneous Fenton, or photo-Fenton processes are discussed. Then, the role of metal doped species for the enhanced efficiency of degradation process is presented. Finally, possible reaction mechanism for the photo-Fenton degradation pollutants in the present of metal doped magnetite is also given.
\end{abstract}

\section{Keywords}

Transition Doped Metal, Metal Doped Magnetite, Photo-Fenton, Role of Doped Metal

\section{Introduction}

The rapid global economic growth has resulted in clean water crisis and environmental pollution since industrial revolution. Literature indicates an increasing trend in generation of wastewaters with recalcitrant characteristics from the many activities of industrial societies [1]. A large number of these pollutants are toxic in nature even at micro quantities [2]. Wastewaters containing these compounds are known to be high in chemical oxygen demand (COD) and low in biological oxygen demand (BOD). These non-biodegradable molecules enter the environment predominantly from mainly industrial activities [3].

Currently, there are various of methods to deal with these issues such as: 
bio-method, chemical-physical method and so on. However, traditional biological methods can effectively treat wastewaters with high biodegradability ratio $\left(\mathrm{BOD}_{5} / \mathrm{COD} \geq 0.4\right)$. In many industries, conventional treatment technologies cannot even produce effluents that meet water quality criteria and effluent limitation guidelines for recalcitrant pollutants [4]. In addition, traditional treatment techniques only succeed in contaminants transfer from liquid phase to solid phase which can cause second pollution. To effectively treat recalcitrant effluent, the scope should encompass degradation as well as mineralization of organic contaminants. That is conversion of probe molecule to its highest stable oxidation state: water, carbon dioxide, and the oxidized inorganic anions of any heteroatoms present, mainly to inorganic acids; or to more easily degradable molecules, that can be easily removed biologically.

Accordingly, advanced oxidation processes (AOPs) are considered as powerful methods for degradation of these pollutants due to their ability for removing almost any organic contaminant [5]. AOPs are considered as water treatment processes at near ambient temperature and pressure that produce very active radicals for degradation of pollutants [6]. In water/wastewater treatment, AOPs generally refer to a group of processes that cover $\mathrm{O}_{3}$ and $\mathrm{H}_{2} \mathrm{O}_{2}$ as oxidants with assistance of light, catalyst (e.g. $\mathrm{Fe}^{2+}, \mathrm{Fe}^{3+}$ and $\mathrm{TiO}_{2}$ ), ultrasonic insertion and/or thermal input and there are several combinations such as Fenton $\left(\mathrm{H}_{2} \mathrm{O}_{2} / \mathrm{Fe}^{2+}\right)$, photo-Fenton $\left(\mathrm{H}_{2} \mathrm{O}_{2} / \mathrm{UV} / \mathrm{Fe}^{2+}\right)$, peroxidation combined with Ultraviolet light $\left(\mathrm{H}_{2} \mathrm{O}_{2} / \mathrm{UV}\right)$, Peroxone $\left(\mathrm{O}_{3} / \mathrm{H}_{2} \mathrm{O}_{2}\right)$. These oxidation processes are cost effective technologies and give rise to non-selective active species that oxidize a wide variety of non-biodegradable compounds [7]. AOPs have been used at various scales for overall organic content (COD) reduction, specific pollutant destruction, sludge treatment, increase of bioavailability of recalcitrant organics, destruction of micropollutants and color and odour removal [8] [9]. However, there are some disadvantages for the application of the traditional homogeneous Fenton and photo-Fenton process, including the requirement of low $\mathrm{pH}$, a significant amount of ferric hydroxide sludge formed in the course of homogeneous Fenton treatment, high leaching ion iron in solution and difficult to separate catalyst after reaction [10]. The heterogeneous photo-Fenton reaction can solve the problem of eliminating and reusing e from the reaction system at the end of the process, but the separation of the solid phase is still a remaining issue [11]. The separation problem is even more important in the case of oxide nanoparticles, which are potentially more reactive because of the favorable surface-to-volume ratio. From this point of view, the fact that magnetite undergoes very easy magnetic separation from aqueous systems makes it a very interesting material to be tested for photo-Fenton reactivity. Recent studies demonstrate that magnetite is the most effective heterogeneous Fenton, photo-Fenton catalyst as compared to other iron oxides, possibly because it is the only one that has $\mathrm{Fe}^{2+}$ in its structure to enhance the production rate of $\mathrm{OH}$ radical [12]. Moreover, its interesting magnetism leads it easy to be separated from the reaction system 
[13]. More recently, it is reported that the introduction of $\mathrm{Mn}, \mathrm{Zn}, \mathrm{Ni}$ [14], $\mathrm{Cr}$ [15], Ti [16] into magnetite structure may strongly promote the Fenton, photo-Fenton degradation of organic contaminants due to a significant promotion of $\mathrm{H}_{2} \mathrm{O}_{2}$ decomposition.

In this work, we give a mini review about using of some currently metal doped magnetite based systems in heterogeneous Fenton, or photo-Fenton processes for degradation of pollutants. Then, the role of metal doped species for the enhanced efficiency of degradation process is discussed. Finally, possible reaction mechanism for the photo-Fenton degradation pollutants in the present of metal doped magnetite is also given.

\section{Fenton Process}

In 1894, French scientist J. H. Fenton found that the oxidation ability of $\mathrm{H}_{2} \mathrm{O}_{2}$ has been greatly increased when $\mathrm{Fe}^{2+}$ catalyse $\mathrm{H}_{2} \mathrm{O}_{2}$ given the acid conditions (pH: 2 - 5). It is called Fenton reaction and the acid solution is called Fenton reagent [17]. It is clear nowadays that the hydroxyl radical $(\bullet \mathrm{OH})$ which has strong oxidation ability is caused by the compound of $\mathrm{Fe}^{2+}$ and $\mathrm{H}_{2} \mathrm{O}_{2}$ [18]. The oxidation potential of hydroxyl radical $(\cdot \mathrm{OH})$ is well known with $2.80 \mathrm{~V}$ which is merely lower than that of $\mathrm{F}_{2}$. The hydroxyl radical $(\bullet \mathrm{OH})$ can destroy structure of organic synthesis because of strong oxidation. The fact make it possible that environmental pollutants can be degradated which can't often be done by other general methods. The mechanisms of generating $\bullet \mathrm{OH}$ in Fenton reaction are as follows [12]:

$$
\begin{gathered}
\mathrm{Fe}(\mathrm{II})+\mathrm{H}_{2} \mathrm{O}_{2} \rightarrow \mathrm{Fe}(\mathrm{III})+\cdot \mathrm{OH}+\mathrm{OH}^{-} \\
\mathrm{Fe}(\mathrm{III})+\mathrm{H}_{2} \mathrm{O}_{2} \rightarrow \mathrm{Fe}\left(\mathrm{HO}_{2}\right)^{2+}+\mathrm{H}^{+} \\
\mathrm{Fe}\left(\mathrm{HO}_{2}\right)^{2+} \rightarrow \mathrm{Fe}(\mathrm{II})+\mathrm{HO}_{2} \\
\mathrm{O}^{2-}+\mathrm{Fe}(\mathrm{III}) \rightarrow \mathrm{Fe}(\mathrm{II})+\mathrm{O}_{2} \\
\cdot \mathrm{OH}+\mathrm{H}_{2} \mathrm{O}_{2} \rightarrow \mathrm{HO}_{2}+\mathrm{H}_{2} \mathrm{O}
\end{gathered}
$$

Thus $\bullet \mathrm{OH}$ is formed from hydrogen peroxide when either $\mathrm{Fe}(\mathrm{II})$ or $\mathrm{Fe}(\mathrm{III})$ is present. The existence of $\bullet \mathrm{OH}$ radicals in Fenton reaction has been proven by monitoring the fluorescence intensity changes [19].

\section{Photo-Fenton Process}

Heterogeneous photo-Fenton process is combination of Fenton reagents $\left(\mathrm{H}_{2} \mathrm{O}_{2}\right.$ and $\left.\mathrm{Fe}^{2+}\right)$ and $\mathrm{UV}$-Vis radiation $(\lambda<600 \mathrm{~nm})$ that gives rise to extra $\bullet \mathrm{OH}$ radicals by two additional reactions. One is the photoreduction of $\mathrm{Fe}^{3+}$ to $\mathrm{Fe}^{2+}$ ions as shown and another is the peroxide photolysis via shorter wavelengths as the following equations $[20]$ :

$$
\begin{gathered}
\mathrm{Fe}^{3+}+\mathrm{H}_{2} \mathrm{O}_{2}+h v \rightarrow \mathrm{Fe}^{3+} \mathrm{OOH}+\mathrm{H}^{+} \\
\mathrm{Fe}^{3+} \mathrm{OOH} \rightarrow \mathrm{Fe}^{2+}+\mathrm{OOH}
\end{gathered}
$$




$$
\begin{gathered}
\mathrm{Fe}^{2+}+\mathrm{H}_{2} \mathrm{O}_{2} \rightarrow \mathrm{Fe}^{3+}+\cdot \mathrm{OH}+\mathrm{OH}^{-} \\
\mathrm{Fe}(\mathrm{OH})^{2+}+h v \rightarrow \mathrm{Fe}^{2+}+\cdot \mathrm{OH} \\
\mathrm{H}_{2} \mathrm{O}_{2}+h v \rightarrow 2 \cdot \mathrm{OH}
\end{gathered}
$$

The photo-Fenton process was reported as more efficient than Fenton treatment. In some cases, use of sunlight instead of UV irradiation reduced the costs [21]. However, this offers a lower degradation rate of pollutants. Acidic conditions (about $\mathrm{pH} 3$ ) were also reported to be favorable and this may be mainly due to the conversion of carbonate and bicarbonate species into carbonic acid, which has a low reactivity with hydroxyl radicals [22].

In the case of conductor catalyst, the reaction mechanism can be proposed as following:

$$
\begin{gathered}
\text { Catalyst }+h v \rightarrow \text { Catalyst }\left(\mathrm{e}_{\mathrm{cb}}^{-}, \mathrm{h}_{\mathrm{vb}}^{+}\right) \\
\mathrm{e}^{-}+\mathrm{H}_{2} \mathrm{O}_{2} \rightarrow \cdot \mathrm{OH}+\mathrm{OH}^{-} \\
\mathrm{e}^{-}+\mathrm{Fe}^{3+} \rightarrow \mathrm{Fe}^{2+} \\
\mathrm{Fe}^{2+}+\mathrm{H}_{2} \mathrm{O}_{2} \rightarrow \mathrm{Fe}^{3+}+\cdot \mathrm{OH}+\mathrm{OH}^{-}
\end{gathered}
$$

Regenerated $\mathrm{Fe}^{3+}$ will take place the reaction to form Fenton reagents leading to more $\cdot \mathrm{OH}$ can be produced [23] as showed in Figure 1.

\section{Metal Doped $\mathrm{Fe}_{3} \mathrm{O}_{4}$ Based Catalysts}

It is recently reported that $\mathrm{Fe}_{3} \mathrm{O}_{4}$ is the effective heterogeneous Fenton, photo Fenton catalyst for removal contaminants in wastewater treatment [24]. The magnetite ability to promote photo-Fenton reactions even under circum neutral $\mathrm{pH}$ conditions, the limited iron leaching and its easy magnetic separation makes magnetite a promising catalyst in wastewater treatment applications. In addition, magnetite can be synthesized in the laboratory by various biotic and abiotic

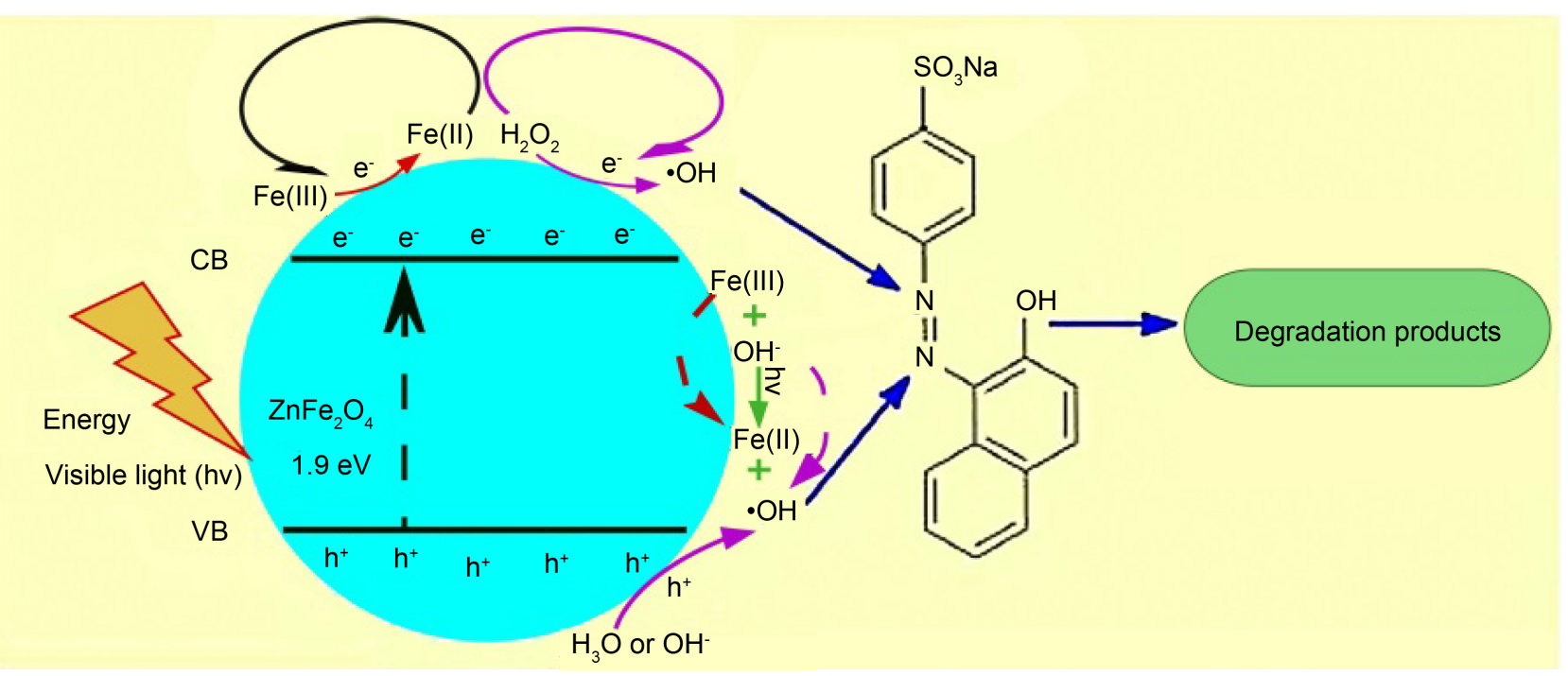

Figure 1. Proposed mechanism of Vis/ $/ \mathrm{ZnF}_{2} \mathrm{O}_{4} / \mathrm{H}_{2} \mathrm{O}_{2}$ system [23]. 
pathways. Abiotic procedures to form magnetite include co-precipitation of soluble Fe (II) and Fe (III) species, oxidation of hydroxylated Fe (II) species and ferric oxides trans-formation. The morphology, crystallography and specific surface area of natural or synthetic magnetite can be controllable synthesized with vary widely route. There are many ways for fabrication of magnetite nanoparticles, such as the hydrothermal route [25], ball mill method [26], polydiallyldimethylamonium chloride method [27], co-precipitation, emulsion method [28], solvothermal [29], etc. For example, iron oxide nanoparticles, with size ranging from 50 to $100 \mathrm{~nm}$, were synthesized by a solvothermal method [11]. The samples with magnetic properties consisting of magnetite $\left(\mathrm{Fe}_{3} \mathrm{O}_{4}\right)$, or by a mixture of magnetite and maghemite $\left(\gamma-\mathrm{Fe}_{2} \mathrm{O}_{3}\right)$, and samples with no magnetism consisting of hematite $\left(\alpha-\mathrm{Fe}_{2} \mathrm{O}_{3}\right)$ can be obtained by a simple route of adjusting precursor materials. The catalytic activity of the materials was studied for the degradation of diphenhydramine using the photo-Fenton process. The results showed that complete degradation of diphenhydramine with $78 \%$ of mineralization was achieved at relatively low leaching of iron species from the catalyst to the aqueous solution (1.9 $\mathrm{mg} \cdot \mathrm{L}^{-1}$ ) with magnetite catalysts (Figure 2).

However, using magnetite in the Fenton, photo-Fenton processes are still limited due to its drawbacks such as a low relative magneticity, poor dispersibility, limited adsorption properties, and low catalytic activity [30] [31]. To come out some of disadvantages of pure magnetite, amount of routes has studied extremely as synthesis with controllable size, morphology, shaped or composite with other materials or non-metal or metal doping. In these routes, metal element doping is reported to be a promising approach due to interesting properties of products.

\subsection{Metal Doped $\mathrm{Fe}_{3} \mathrm{O}_{4}$ Based Catalysts for Fenton, Photo-Fenton Degradation}

Recently, studying on metal doped magnetite based catalyst has paid more and

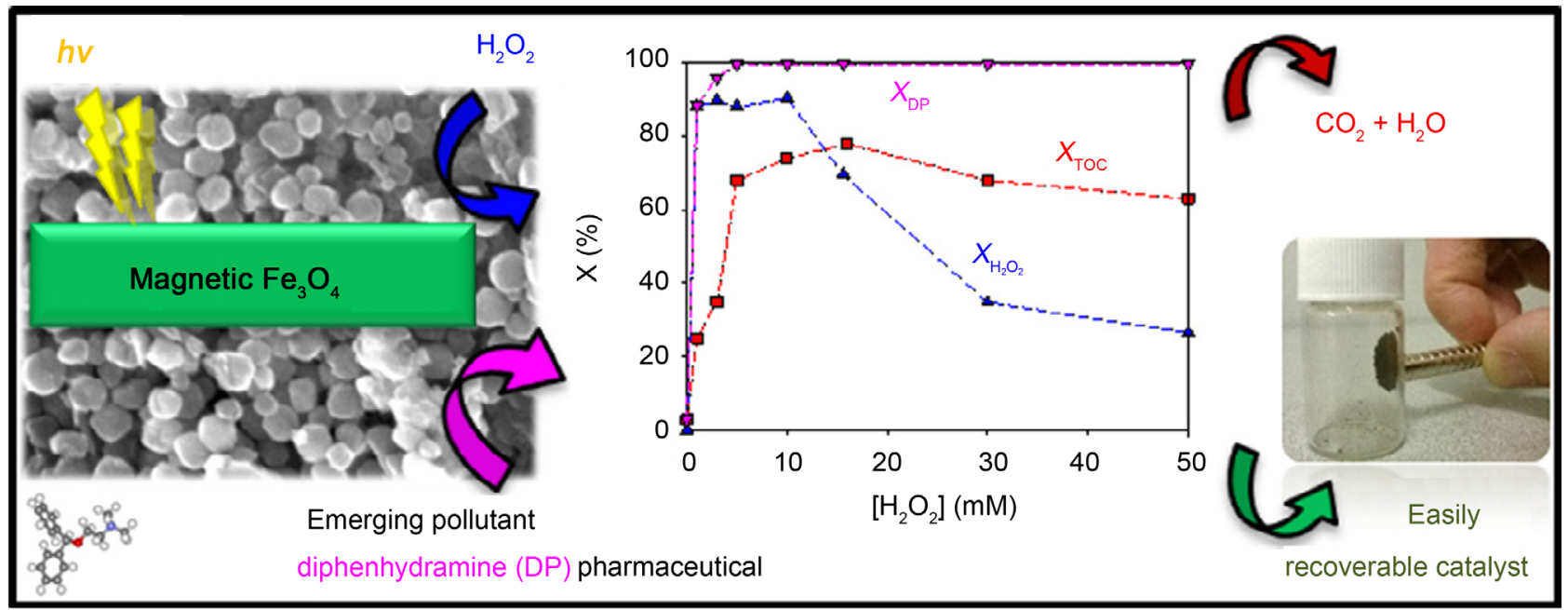

Figure 2. Using magnetite in the photo-Fenton degradation of diphenhydramine [11]. 
more attention of researchers. Based on the previous reports in this filed, it is can be seen that the introduction of $\mathrm{Co}, \mathrm{Cr}$ [32], $\mathrm{Ti}, \mathrm{Zn}$ and $\mathrm{Mn}$ into magnetite structure may strongly promote the Fenton, photo-Fenton degradation of organic contaminants due to a significant promotion of $\mathrm{H}_{2} \mathrm{O}_{2}$ decomposition. Our previous report showed $\mathrm{Zn}$ doped magnetite has higher capacity in the photo-Fenton degradation of cephalexin and rhodamine B compared to pure magnetite. Hongping Hea et al. have prepared substituted magnetite with chromium via a simple precipitation-oxidation method. The applicability of series of substituted magnetite as Fenton catalyst in the degradation of cationic (MB) and anionic (acid orange II) model dyes was investigated [33]. Cr incorporation significantly improved the catalytic activity of magnetite in heterogeneous Fenton reaction. After $200 \mathrm{~min}$ of degradation, the $\mathrm{MB}$ removal rate was 59.3\%, 71.3\%, 87.0\% and 95.2\% in the presence of $\mathrm{Fe}_{2.82} \mathrm{Cr}_{0.18} \mathrm{O}_{4}, \mathrm{Fe}_{2.67} \mathrm{Cr}_{0.33} \mathrm{O}_{4}, \mathrm{Fe}_{2.53} \mathrm{Cr}_{0.47} \mathrm{O}_{4}$ and $\mathrm{Fe}_{2.33} \mathrm{Cr}_{0.67} \mathrm{O}_{4}$, respectively (as shown in Figure 3). A series of Mn doped magnetite was showed the enhanced efficiency in photo-Fenton degradation of $\mathrm{MB}$ compared to non-doped magnetite (Figure 4). It is noted that magnetite doping $1 \% \mathrm{Mn}$ has higher catalytic capability than that of $10 \%$ [34].

From the fact that in most natural cases, more than two kinds of metals are simultaneously introduced into magnetites in geological processes so studies on the influence of co-substituting metals on the structure and properties of magnetite, especially the surface reactivity and catalytic activity have been conducted widely [35]. The application of V-Ti co-doped magnetite in heterogeneous Fenton reaction showed that the incorporation of $\mathrm{Ti}^{4+}$ and $\mathrm{V}^{3+}$ can greatly enhance UV-Fenton catalytic activity of magnetite during the MB decolorizaition [36]. Figure 5 revealed that $\mathrm{Ti}$ or $\mathrm{V}$ doped magnetite exhibited the higher catalyst in

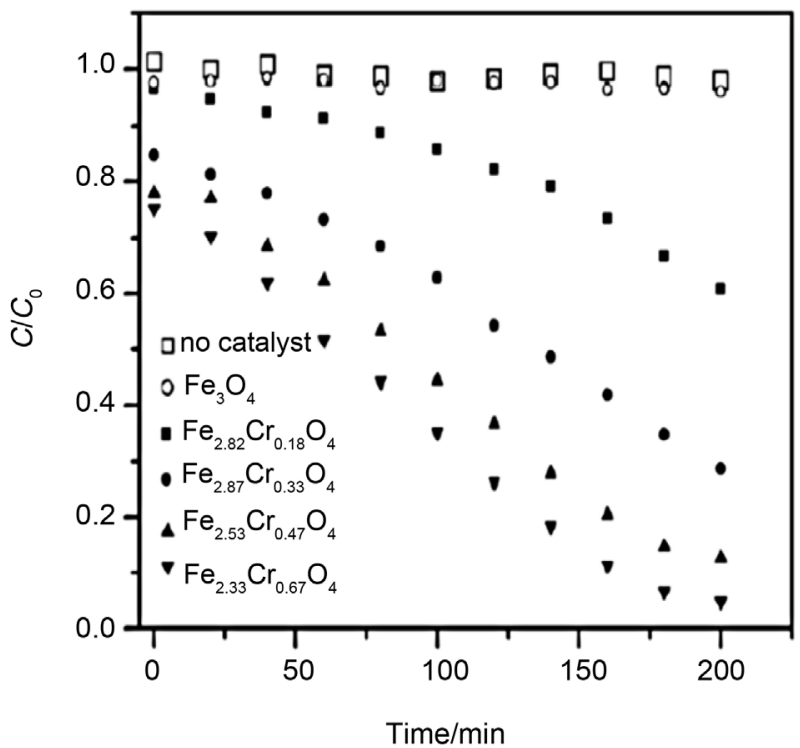

(a)

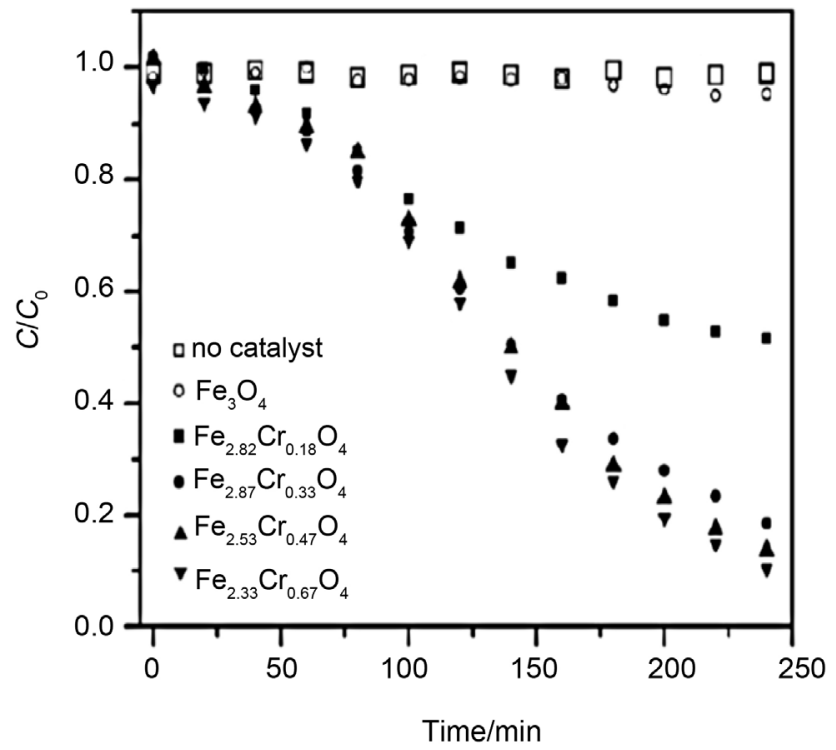

(b)

Figure 3. (a) Decolorization of methylene blue; (b) acid orange II through heterogeneous Fenton reaction catalyzed by $\mathrm{Fe}_{3-\mathrm{x}} \mathrm{Cr}_{\mathrm{x}} \mathrm{O}_{4}$ $\left(\mathrm{C}_{0}=0.2 \mathrm{mmol} \cdot \mathrm{L}^{-1}, 80 \mathrm{mmol} \cdot \mathrm{L}^{-1}\right.$ of $\mathrm{H}_{2} \mathrm{O}_{2}, 1.0 \mathrm{~g} \cdot \mathrm{L}^{-1}$ of catalyst, $\left.250 \mathrm{~mL}, \mathrm{pH} 7.0,25^{\circ} \mathrm{C}\right)$ [33]. 


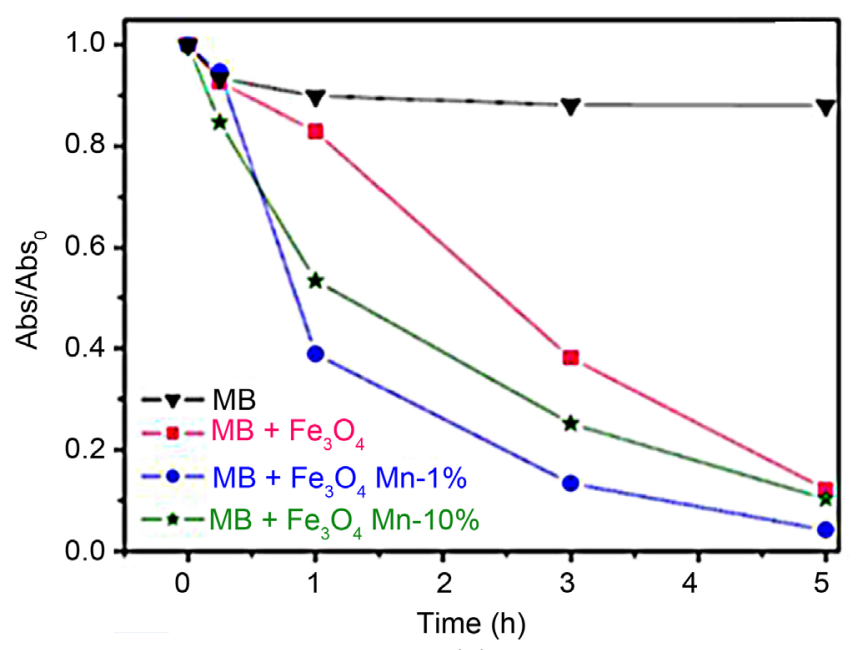

(a)

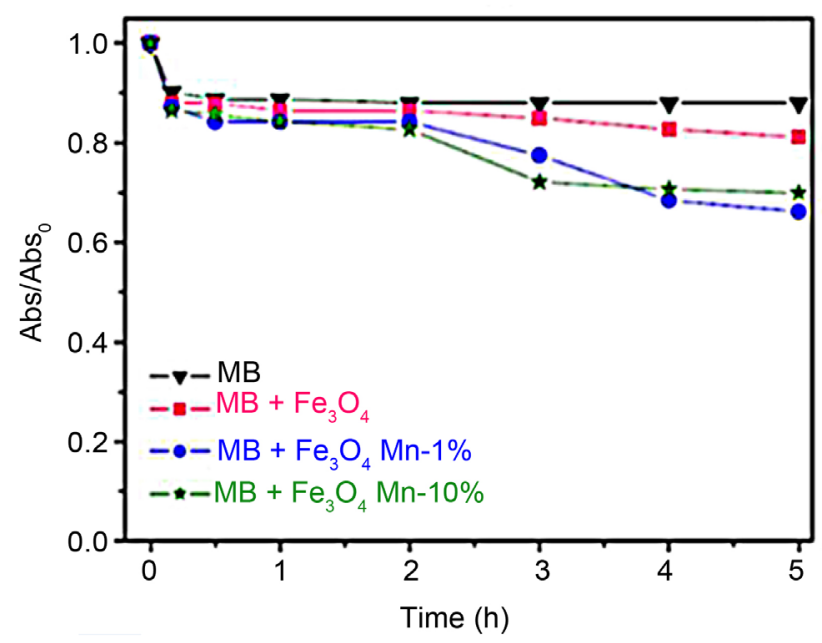

(b)

Figure 4. Influence of $\mathrm{Mn}$ incorporation level of magnetite on the photocatalytic dis-coloration of methylene blue in presence of $\mathrm{H}_{2} \mathrm{O}_{2}$ : (a) irradiated by UV-A and (b) in the dark [34].
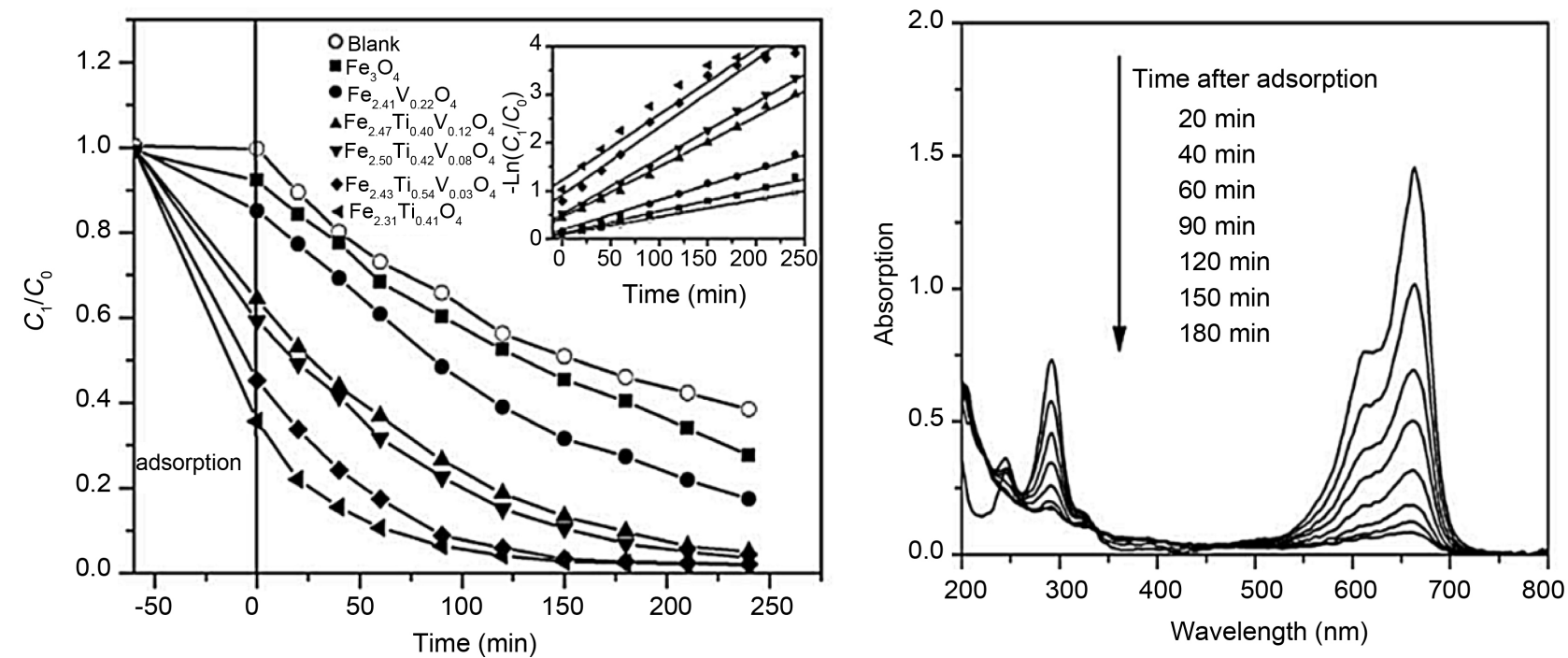

Figure 5. UV-Fenton degradation and the changes of absorption spectra of $M B$ catalyzed by synthetic magnetite samples $\left(\mathrm{C}_{0}=0.2\right.$ $\mathrm{mmol} \cdot \mathrm{L}^{-1}, 10 \mathrm{mmol} \cdot \mathrm{L}^{-1}$ of $\mathrm{H}_{2} \mathrm{O}_{2}, 1.0 \mathrm{~g} \cdot \mathrm{L}^{-1}$ of catalyst, $\left.\mathrm{UV}(6 \mathrm{~W}, 365 \mathrm{~nm}), 500 \mathrm{~mL}, \mathrm{pH} 7.0,25^{\circ} \mathrm{C}\right)$. Inset: UV-Fenton degradation processes fitted by pseudo first-order kinetics [38].

the Fenton-degradation of MB. Through a series of experiments about the degradation and mineralization of two dyes (MO and $\mathrm{MB}$ ) in heterogeneous Fenton using modified magnetite nanoparticles $\left(\mathrm{Fe}_{3-\mathrm{x}-\mathrm{y}} \mathrm{Nb}_{\mathrm{x}} \mathrm{Mo}_{\mathrm{y}} \mathrm{O}_{4}\right)$, Shima Rahim Pouran et al. found out that co-doped Nb-Mo-magnetite nanoparticles showed highest activity in comparison to single $\mathrm{Nb}$ - and Mo-substituted magnetite samples [37].

The results from previous reports have indicated that metal doping with magnetite can be a promising approach for improving the efficient degradation of contaminants in the Fenton and photo-Fenton due to high degradation efficiency around neutral $\mathrm{pH}$, easy recycle of catalyst in practical wastewater purifi- 
cation. It is also because that metal doping magnetite can be easy to controllable synthesis. The obtained products have many interesting catalytic and magnetic properties. The different characterization of these obtained products depends tightly on not only the prepared route but also the metal doping.

\subsection{Role of Metal Doped Species and Compare Enhanced Efficiency of Degradation Process}

So far, several single-metal cations, such as $\mathrm{Ti}^{4+}, \mathrm{V}^{3+}, \mathrm{Mn}^{2+}, \mathrm{Co}^{2+}, \mathrm{Cr}^{3+}, \mathrm{Zn}^{2+}$, and co-substituting metals have been reported as active components to increase the Fenton, photo-Fenton catalytic activity of magnetite. It has been widely acknowledged that the catalytic activity of magnetite is greatly dependent on the species, valence and occupancy of substituting metals. Substituting metals exhibiting thermo-dynamically favorable redox pairs can improve the catalytic activity of magnetite by accelerating the electronic transfer to produce the active species $\mathrm{Fe}^{2+}$ for the Fenton reaction [33]. Effect of metal doped that exhibiting thermo-dynamically favorable redox pairs has proved via experiments reported by Rochel M. Lago et al. [39]. The experiments results showed that a low activity for methylene blue or chlorobenzen oxidation in the presence of $\mathrm{Fe}_{2: 46} \mathrm{Ni}_{0: 54} \mathrm{O}_{4}$, with only $10 \%$ color reduction after $50 \mathrm{~min}$ but $\mathrm{Mn}$ and Co substituted magnetites showed very high oxidation activity with complete discoloration of the solution in 5 and $10 \mathrm{~min}$, respectively. This constraint efficiency can be explained by the different role of substituted metal. For nickel it can be considered that only the $\mathrm{Ni}^{2+}$ species is stable and for this reason cannot initiate the reaction like $\mathrm{Fe}^{2+}$ and $\mathrm{Mn}^{2+}$. Another reason for low efficiency of $\mathrm{Ni}$ doped magnetite is that $\mathrm{Ni}^{2+}$ can replace mainly $\mathrm{Fe}^{2+}$ in the magnetite structure leading to the reaction inhibited since $\mathrm{Fe}^{2+}$ is responsible for the initial step. On the other hand, cobalt and manganese exhibit the redox pairs $\mathrm{Co}^{2+} / \mathrm{Co}^{3+}$ and $\mathrm{Mn}^{2+} / \mathrm{Mn}^{3+}$, which could also produce radicals according to the reactions:

$$
\begin{aligned}
& \mathrm{Co}_{\text {surf }}^{2+}+\mathrm{H}_{2} \mathrm{O}_{2} \rightarrow \mathrm{Co}_{\text {surf }}^{3+}+\mathrm{OH}^{-}+\cdot \mathrm{OH} \\
& \mathrm{Mn}_{\text {surf }}^{2+}+\mathrm{H}_{2} \mathrm{O}_{2} \rightarrow \mathrm{Mn}_{\text {surf }}^{3+}+\mathrm{OH}^{-}+\cdot \mathrm{OH}
\end{aligned}
$$

The strong effect of Co and Mn substitution it could also be considered a thermodynamically favorable electron transfer during the reaction shown by the following equations:

$$
\begin{aligned}
\mathrm{Fe}^{2+}+\mathrm{Co}^{3+} & \rightarrow \mathrm{Fe}^{3+}+\mathrm{Co}^{2+} \\
\mathrm{Fe}^{2+}+\mathrm{Mn}^{3+} & \rightarrow \mathrm{Fe}^{3+}+\mathrm{Mn}^{2+}
\end{aligned}
$$

The efficient regeneration of the surface $\mathrm{Co}^{2+}$ or $\mathrm{Mn}^{2+}$ species by this process would be responsible for the remarkable increase an activity of $\mathrm{H}_{2} \mathrm{O}_{2}$ decomposition and organic oxidation observed for these materials. Radicalar mechanism proposal for the activation of $\mathrm{H}_{2} \mathrm{O}_{2}$ by $\mathrm{Fe}^{2+}$ or meal doping of magnetite can be shown in Figure 6.

Magnetite is a semiconductor with a narrow band gap $(0.1 \mathrm{eV})$ and shows a very high conductivity with almost metallic character which is important for 


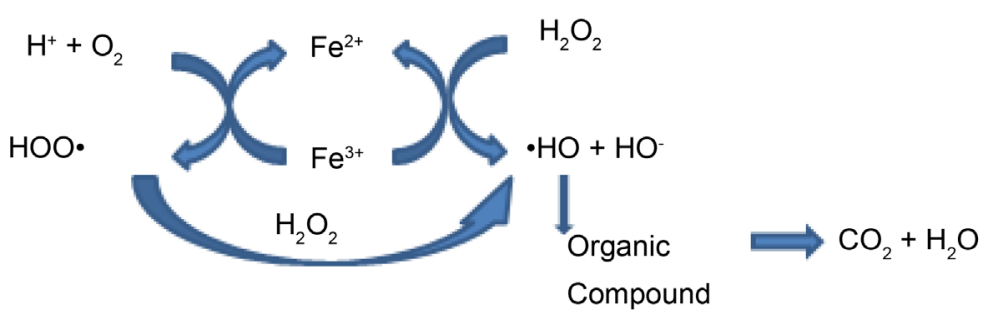

(a)

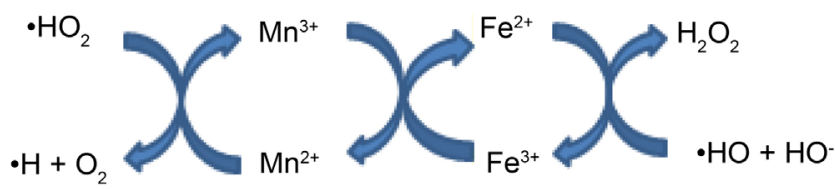

(b)

Figure 6. (a) Radicalar mechanism proposal for the activation of $\mathrm{H}_{2} \mathrm{O}_{2}$ by $\mathrm{Fe}^{2+}$ of Magnetite [32]; (b) Proposed mechanism for the participation of $\mathrm{Mn}^{2+}$ in the Fenton reaction.

electron transport. Metal doping in magnetite is also expected as reactor for controllable synthesis of magnetite which the metal doped present can be change chemical and physical properties of initial magnetic leading to enhance catalytic activity. Our previous showed that diffusion of $\mathrm{Zn}$ into crystal $\mathrm{Fe}_{3} \mathrm{O}_{4}$ can form new magnetite exposing interesting properties as optical absorption spectra, area surface and unique structure, resulting in higher capacity of photo-Fenton degradation of pollutants [40]. Recently, Hongping He reported that $\mathrm{Cr}$ substitution greatly increases the catalytic activity of magnetite in the heterogeneous Fenton reaction, but its enhancement extent depends on the chromium substitution level [33]. The catalytic activity relies on the octahedral cations rather than the tetrahedral ones, as the octahedral sites are almost exclusively exposed at the surface of the spinel structure (as Figure 7).

The obtained novel insights on role of metal doped species are of high importance for the designed synthesis as well as the utilization of substituted magnetite in the field of wastewater treatment.

\section{Reaction Mechanism}

From recent reports in literature on the transition metal oxide promoted $\mathrm{H}_{2} \mathrm{O}_{2}$ decomposition in the absent of light, a possible reaction mechanism can be proposed. The $\mathrm{H}_{2} \mathrm{O}_{2}$ decomposition in participate of doped metal is take place by two possible reaction pathways [41]: 1) the surface oxygen vacancies $\left(\mathrm{Va}_{\text {surf }}\right)$ mechanism and 2) the radicalar mechanism. In the first route, a $\mathrm{H}_{2} \mathrm{O}_{2}$ molecule will be actived by oxygen vacancy on the oxide surface participates to form $\mathrm{O}_{2}$ (Equations (19) and (20)):

$$
\begin{gathered}
\mathrm{Va}_{\text {surf }}+\mathrm{H}_{2} \mathrm{O}_{2} \rightarrow \mathrm{Va}-\mathrm{O}_{\text {surf }}+\mathrm{H}_{2} \mathrm{O} \\
\mathrm{Va}-\mathrm{O}_{\text {surf }}+\mathrm{H}_{2} \mathrm{O}_{2} \rightarrow \mathrm{Va}_{\text {surf }}+\mathrm{H}_{2} \mathrm{O}+\mathrm{O}_{2}
\end{gathered}
$$

The radical mechanism will be initiated by a reaction of $\mathrm{H}_{2} \mathrm{O}_{2}$ with a partially 


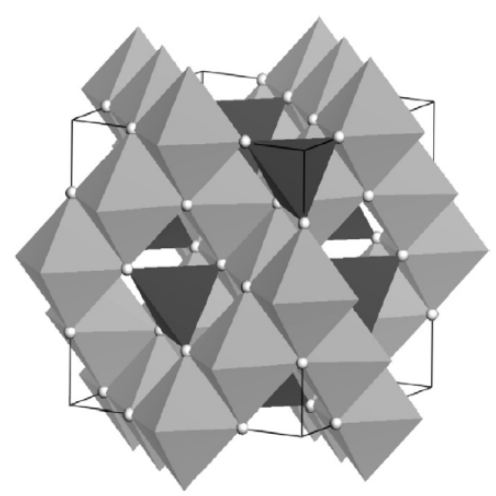

Figure 7. A unit cell of magnetite [33].

reduced surface pieces according to a Fenton like reaction or conduct reduce-oxidation reactions between redox pairs:

$$
\begin{gathered}
\mathrm{M}_{\text {surf }}^{2+}+\mathrm{H}_{2} \mathrm{O}_{2} \rightarrow \mathrm{M}_{\text {surf }}^{3+}+\mathrm{OH}^{-}+\cdot \mathrm{OH} \\
\mathrm{Fe}^{2+}+\mathrm{M}^{3+} \rightarrow \mathrm{Fe}^{3+}+\mathrm{M}^{2+}
\end{gathered}
$$

In the radical route, $\mathrm{O}_{2}$ can be form and the formation of $\mathrm{O}_{2}$ can be proposed simply via the hydroperoxide radical:

$$
\begin{gathered}
\mathrm{H}_{2} \mathrm{O}_{2}+\cdot \mathrm{OH} \rightarrow \mathrm{H}_{2} \mathrm{O}+\cdot \cdot \mathrm{OOH} \\
\mathrm{Fe}_{\text {surf }}^{3+}+\cdot \mathrm{OOH} \rightarrow \mathrm{Fe}_{\text {surf }}^{2+}+\mathrm{H}^{+}+\mathrm{O}_{2}
\end{gathered}
$$

Due to magnetite, $\mathrm{Fe}_{3} \mathrm{O}_{4}$, is a semiconductor with a narrow band gap $(0.1 \mathrm{eV})$ so in the present of light (UV/visible light), a following reaction mechanism suggested for understanding photo-Fenton reaction in the present of $\mathrm{Zn}$ doped $\mathrm{Fe}_{3} \mathrm{O}_{4}$ HSMSs catalyst [42]. Under visible light irradiation, electron/hole pairs can be photogenerated in the catalyst. Then, photogenerated electrons can be trapped by $\mathrm{H}_{2} \mathrm{O}_{2}$ leading to $\cdot \mathrm{OH}$. Simultaneously, they can be trapped by $\mathrm{Fe}^{3+}$ on surface of catalyst forming $\mathrm{Fe}^{2+}$. Then more $\bullet \mathrm{OH}$ can be produced that resulting in reaction between formed $\mathrm{Fe}^{2+}$ with $\mathrm{H}_{2} \mathrm{O}_{2}$.

$$
\begin{gathered}
\text { Catalyst }+h v \rightarrow \text { Catalyst }\left(\mathrm{e}_{\mathrm{cb}}^{-}, h_{\mathrm{vb}}^{+}\right) \\
\mathrm{e}^{-}+\mathrm{H}_{2} \mathrm{O}_{2} \rightarrow \cdot \mathrm{OH}+\mathrm{OH}^{-} \\
\mathrm{e}^{-}+\mathrm{Fe}^{3+} \rightarrow \mathrm{Fe}^{2+} \\
\mathrm{Fe}^{2+}+\mathrm{H}_{2} \mathrm{O}_{2} \rightarrow \mathrm{Fe}^{3+}+\cdot \mathrm{OH}+\mathrm{OH}^{-}
\end{gathered}
$$

\section{Conclusion}

Based on the reports on magnetite increasing intensity in the literature recently, it can be seen that the introduction of $\mathrm{Co}, \mathrm{Cr}, \mathrm{Ti}, \mathrm{Zn}$ and $\mathrm{Mn}$ into magnetite structure may strongly promote the Fenton, photo-Fenton degradation of organic contaminants due to a significant promotion of $\mathrm{H}_{2} \mathrm{O}_{2}$ decomposition. Moreover, role of metal doping in the most case have been proposed. A possible reaction mechanism suggested for understanding photo-Fenton reaction in the present of metal doped magnetite have discussed in this work. However, reac- 
tion mechanism with participation of transition metal doping need make clearer by more studies. In particular, how to synthesis metal doped magnetite based materials to meet designed requirements plays a very important role in this field. These new insights are important direction for the controllable synthesis and the environmental application of metal substituted magnetites in the purification of organic contaminant textile wastewater.

\section{References}

[1] Pouran, S.R., Abdul, A.R. and Wan, D.W.M.A. (2015) Review on the Main Advances in Photo-Fenton Oxidation System for Recalcitrant Wastewaters. Journal of Industrial and Engineering Chemistry, 21, 53-69. https://doi.org/10.1016/j.jiec.2014.05.005

[2] Minella, M., Marchetti, G., Laurentiis, D.E., Malandrino, M., Maurino, V., Minero, C., Vione, D. and Hanna, K. (2014) Photo-Fenton Oxidation of Phenol with Magnetite as Iron Source. Applied Catalysis B: Environmental, 154-155, 102-109. https://doi.org/10.1016/j.apcatb.2014.02.006

[3] Clarizia, D.R., Somma, I.D., Marotta, R. and Andreozzi, R. (2017) Homogeneous pho-to-Fenton Processes at Near Neutral pH: A Review. Applied Catalysis B: Environmental, 2017, 209.

[4] Mirzaei, Z.C., Fariborz, H. and Laleh, Y. (2017) Removal of Pharmaceuticals from Water by Homo/Heterogonous Fenton-Type Processes. Chemosphere, 174, 665-688. https://doi.org/10.1016/j.chemosphere.2017.02.019

[5] Giannakis, M.I., Dorothee, S., José, A.S., Pilar, F.I. and César, P. (2016) Solar Disinfection Is an Augmentable, in situ-Generated Photo-Fenton Reaction-Part 2: A Review of the Applications for Drinking Water and Wastewater Disinfection. Applied Catalysis B: Environmental, 198, 431-446. https://doi.org/10.1016/j.apcatb.2016.06.007

[6] Babuponnusami, A. and Muthukuma, K. (2014) A Review on Fenton and Improvements to the Fenton Process for Wastewater Treatment. Journal of Environmental Chemical Engineering, 2, 557-572. https://doi.org/10.1016/j.jece.2013.10.011

[7] Chong, M.N., Jin, B., Chow, C.W. and Saint, C. (2010) Recent Developments in Photocatalytic Water Treatment Technology: A Review. Water Research, 44, 2997-3027. https://doi.org/10.1016/j.watres.2010.02.039

[8] Ahmed, S., Rasul, M.G., Martens, W.N., Brown, R. and Hashib, M.A. (2010) Heterogeneous Photocatalytic Degradation of Phenols in Wastewater: A Review on Current Status and Developments. Desalination, 261, 3-18. https://doi.org/10.1016/j.desal.2010.04.062

[9] Giannakis, M.I., Dorothee, S., Jose, A.S. and César, P. (2016) Solar Disinfection is an augmentable, in situ-Generated Photo-Fenton Reaction-Part 1: A Review of the Mechanisms and the Fundamental Aspects of the Process. Applied Catalysis B: Environmental, 199, 199-223. https://doi.org/10.1016/j.apcatb.2016.06.009

[10] Zhang, G., Guo, S. and Yu, J.C. (2015) Enhanced Photo-Fenton Degradation of Rhodamine B Using Graphene Oxide-Amorphous $\mathrm{FePO}_{4}$ as Effective and Stable Heterogeneous Catalyst. Journal of Colloid and Interface Science, 448, 460-466. https://doi.org/10.1016/j.jcis.2015.02.005

[11] Martínez, L.M., Pereira, N., Lima, R., Faria, J.L., Gomes, H.T. and Silva, A.M. (2015) Degradation of Diphenhydramine by Photo-Fenton Using Magnetically Recoverable Iron Oxide Nanoparticles as Catalyst. Chemical Engineering Journal, 261, 45-52. 
https://doi.org/10.1016/j.cej.2014.04.117

[12] Voelker, W.P. (2003) Rates of Hydroxyl Radical Generation and Organic Compound Oxidation in Mineral-Catalyzed Fenton-Like Systems. Environmental Science Technology, 37, 1150-1158. https://doi.org/10.1021/es020874g

[13] Abbas, M., Rao, P.B. and Kim, C. (2014) Shape and Size-Controlled Synthesis of Ni Zn Ferrite Nanoparticles by Two Different Routes. Materials Chemistry and Physics, 147, 443-451. https://doi.org/10.1016/j.matchemphys.2014.05.013

[14] Abbas, M., Torati, S.R., Rao, B.P., Abdel-Hamed, M.O. and Kim, C. (2015) Size Controlled Sonochemical Synthesis of Highly Crystalline Superparamagnetic $\mathrm{Mn}-\mathrm{Zn}$ Ferrite Nanoparticles in Aqueous Medium. Journal of Alloys and Compounds, 644, 774-782. https://doi.org/10.1016/j.jallcom.2015.05.101

[15] Cynthia, W.C., Warner, L., Mackie, E.K., Neiner, D., Saraf, V.L. and Addleman, S.R. (2012) Manganese Doping of Magnetic Iron Oxide Nanoparticles: Tailoring Surface Reactivity for a Regenerable Heavy Metal Sorbent. Langmuir, 28, 3931-3937. https://doi.org/10.1021/la2042235

[16] Borhan, A.I., Samoila, P., Hulea, V., Iordan, A.R. and Palamaru, M.N. (2014) Correlation between Structural, Magnetic and Electrical Properties of Nanocrystalline $\mathrm{Al} 3+$ Substituted Zinc Ferrite. Journal of the Taiwan Institute of Chemical Engineers, 45, 1655-1660.

[17] Yang, S., He, H., Wu, D., Chen, D., Liang, X., Qin, Z., Fan, M., Zhu, J. and Yuan, P. (2009) Decolorization of Methylene Blue by Heterogeneous Fenton Reaction Using $\mathrm{Fe}_{3}-\mathrm{xTixO}_{4}(0 \leq \mathrm{x} \leq 0.78)$ at Neutral $\mathrm{pH}$ Values. Applied Catalysis B: Environmental, 89, 527-535. https://doi.org/10.1016/j.apcatb.2009.01.012

[18] Fenton, H.J. (1894) Oxidation of Tartaric Acid in Presence of Iron. Journal of the Chemical Society Journal, 65, 899-910. https://doi.org/10.1039/CT8946500899

[19] Benitez, J.L., Real, F.J., Rubio, F.J. and Leal, A.I. (2001) The Role of Hydroxyl Radicals for the Decomposition of p-Hydroxyl Phenylacetic Acid in Aqueous Solutions. Water Research, 35, 1338-1343. https://doi.org/10.1016/S0043-1354(00)00364-X

[20] Zhang, G., Guo, S. and $\mathrm{Yu}$, J. (2013) Graphene Oxide- $\mathrm{Fe}_{2} \mathrm{O}_{3}$ Hybrid Material as Highly Efficient Heterogeneous Catalyst for Degradation of Organic Contaminants. Carbon, 60, 437-444. https://doi.org/10.1016/j.carbon.2012.08.040

[21] Gao, Y., Gan, H., Zhang, G. and Guo, Y. (2013) Visible Light Assisted Fenton-Like Degradation of Rhodamine B and 4-Nitrophenol Solutions with a Stable Poly-Hydroxyl-Iron/Sepiolite Catalyst. Chemical Engineering Journal, 217, 221-230. https://doi.org/10.1016/j.cej.2012.11.115

[22] Muhammad, U. and Mohd, S.Y. (2010) Trends in the Use of Fenton, Electro-Fenton and Pho-to-Fenton for the Treatment of Landfill Leachate. Waste Management, 30, 2113-2121. https://doi.org/10.1016/j.wasman.2010.07.003

[23] Liu, S.Q., Feng, L.R., Xu, N., Chen, Z.G. and Wang, X.M. (2012) Magnetic Nickel Ferrite as a Heterogeneous Photo-Fenton Catalyst for the Degradation of Rhodamine B in the Presence of Oxalic Acid. Chemical Engineering Journal, 203, 432-439. https://doi.org/10.1016/j.cej.2012.07.071

[24] Cai, C., Zhang, Z., Liu, J., Shan, N., Zhang, H. and Dionysiou, D.D. (2016) Visible Light-Assisted Heterogeneous Fenton with $\mathrm{ZnFe}_{2} \mathrm{O}_{4}$ for Thedegradation of Orange II in Water. Applied Catalysis B: Environmental, 182, 456-468. https://doi.org/10.1016/j.apcatb.2015.09.056

[25] Munoz, M., Pedro, D.Z.M., Casas, J.A. and Rodriguez, J.J. (2015) Preparation of Magnetite-Based Catalysts and Their Application in Heterogeneous Fenton Oxidation-A Review. Applied Catalysis B: Environmental, 176-177, 249-265. 
https://doi.org/10.1016/j.apcatb.2015.04.003

[26] Peng, S., Li, Q., Jian, J., Sun, Y. and Jiwuer, J. (2009) Hydrothermal Growth of Octahedral $\mathrm{Fe}_{3} \mathrm{O}_{4}$ Crystals. Particuology, 7, 35-38.

https://doi.org/10.1016/j.partic.2008.11.010

[27] Acisli, A., Karaca, S., Karimi, A. and Dogan, E. (2017) Combination of Ultrasonic and Fenton Processes in the Presence of Magnetite Nanostructures Prepared by High Energy Planetary Ball Mill. Ultrasonics Sonochemistry, 34, 754-762. https://doi.org/10.1016/j.ultsonch.2016.07.011

[28] Wang, L., Wang, H., Yang, W., Fu, Y., Zhou, W., Yu, W., Xiang, K., Su, Z., Dai, S. and Chai, L. (2013) Controllable Synthesis of Hierarchical Porous $\mathrm{Fe}_{3} \mathrm{O}_{4}$ Particles Mediated by Poly(diallyldimethylammonium Chloride) and Their Application in Arsenic Removal. ACS Applied Materials \& Interfaces, 5, 12449-12459. https://doi.org/10.1021/am403533v

[29] Su, C. (2017) Removal of Ionizable Aromatic Pollutants from Contaminated Water using Nano $\gamma-\mathrm{Fe}_{2} \mathrm{O}_{3}$ Based Magnetic Cationic Hydrogel: Sorptive Performance, Magnetic Separation and Reusability. Journal Hazardous Materials, 322, 48-84. https://doi.org/10.1016/j.jhazmat.2016.06.060

[30] Zhang, M., Zhang, Q., Li, Y. and Wang, H. (2009) The Formation of Magnetite Nanoparticles on the Sidewalls of Multi-Walled Carbon Nanotubes Composite. Science Technology, 69, 633-638.

[31] Liu, J., Bin, Y. and Matsuo, M. (2012) Magnetic Behavior of Zn-Doped $\mathrm{Fe}_{3} \mathrm{O}_{4} \mathrm{Na}$ noparticles Estimated in Terms of Crystal Domain Size. The Journal of Physical Chemistry C, 116, 134-143. https://doi.org/10.1021/jp207354s

[32] Shi, D., Shen, B., Cui, C., Lu, L., Wang, L. and Zhang, J. (2016) Synthesis of Yolk-Shell Structured $\mathrm{Fe}_{3} \mathrm{O}_{4}$ Void CdS Nanoparticles: A General and Effective Structure Design for Photo-Fenton Reaction. ACS Applied Materials and Interfaces, 8, 20831-20838. https://doi.org/10.1021/acsami.6b07644

[33] Magalhães, F., Pereira, M.C., Botrel, S.E., Fabris , J.D., Macedo, W.A., Mendonça, R., Lago, R.M. and Oliveira, L.C.A. (2007) Cr-Containing Magnetites $\mathrm{Fe}_{3}-\mathrm{xCrxO}$ : The Role of $\mathrm{Cr}^{3+}$ and $\mathrm{Fe}^{2+}$ on the Stability and Reactivity towards $\mathrm{H}_{2} \mathrm{O}_{2}$ Reactions. Applied Catalysis A: General, 332, 115-123. https://doi.org/10.1016/j.apcata.2007.08.002

[34] Liang, X., Hea, H., Peng, Y., Zhu, J., Zhu, S. and Jiang, Z. (2012) The Application of Chromium Substituted Magnetite as Heterogeneous Fenton Catalyst for the Degradation of Aqueous Cationic and Anionic Dyes. Chemical Engineering Journal, 191, 177-184. https://doi.org/10.1016/j.cej.2012.03.001

[35] Hudson, P.H., Carvalho, W.P., Sandra, H.P., Celso, V.S. and Eduardo, F.M. (2014) Improvement of the Photocatalytic Activity of Magnetite by Mnincorporation. Materials Science and Engineering B, 181, 64-69.

https://doi.org/10.1016/j.mseb.2013.11.008

[36] Liang, X., Zhu, S., Zhu, J., Yuan, P., He, H. and Zhang, J. (2010) The Decolorization of Acid Orange II in Non-Homogeneous Fenton Reaction Catalyzed by Natural Vanadium-Titanium Magnetite. Journal of Hazardous Materials, 181, 112-120. https://doi.org/10.1016/j.jhazmat.2010.04.101

[37] Shima, R.P., Abdul Aziz, A.R., Wan, M.A. and Mohammad, S. (2016) Ultrasound and UV Assisted Fenton Treatment of Recalcitrant Waste Waters using Transition Metal-Substituted-Magnetite Nanoparticles. Journal of Molecular Liquids, 222, 1076-1084. https://doi.org/10.1016/j.molliq.2016.07.120

[38] Shima, R.P., Wan, M.A. and Shafeeyan, M.S. (2015) Effects of Niobium and Mo- 
lybdenum Impregnation on Adsorption Capacity and Fenton Catalytic Activity of Magnetite. RSC Advances, 5, 87535-87549.

https://doi.org/10.1016/j.molliq.2016.07.120

[39] Liang, X., Zhu, S., Ma, L., Yuan, P., Zhu, J. and He, H. (2012) The Contribution of Vanadium and Titanium on Improving Methylene Blue Decolorization through Heterogeneous UV-Fenton Reaction Catalyzed by Their Co-Doped Magnetite. Journal of Hazardous Materials. https://doi.org/10.1016/j.jhazmat.2011.11.007

[40] Costa, R.C., Lelis, M., Oliveira, L.C., Fabris, J.D., Ardisson, J.D., Rios, R.R., Silva, C.N. and Lago, R.M. (2003) Remarkable Effect of Co and Mn on the Activity of $\mathrm{Fe}_{3}-\mathrm{xMxO}_{4}$ Promoted Oxidation of Organic Contaminants in Aqueous Medium with H2O2. Catalysis Communications, 4, 525-529.

https://doi.org/10.1016/j.jhazmat.2011.11.007

[41] Nguyen, X.S., Zhang, G. and Yang, X. (2017) Mesocrystalline Zn-Doped Fe3O4 Hollow Sub-Microspheres: Formation Mechanism and Enhanced Photo-Fenton Catalytic Performance. ACS Applied Materials and Interfaces, 9, 8900-8909.

https://doi.org/10.1021/acsami.6b16839

[42] Costa, R.C., Lelis, M.F., Oliveria, L.C., Fabris, J.D., Ardisson, J.D. Rios, R.R., Silva, C.N. and Lago, R.M. (2006) Novel Active Heterogeneous Fenton System Based on $\mathrm{Fe}_{3}-\mathrm{xMxO}_{4}$ (Fe, Co, Mn, Ni): The Role of $\mathrm{M} 2+$ Species on the Reactivity towards $\mathrm{H} 2 \mathrm{O} 2$ Reactions. Journal Hazardous Materials, 129, 171-178.

https://doi.org/10.1016/j.jhazmat.2005.08.028 